This item was submitted to Loughborough's Research Repository by the author.

Items in Figshare are protected by copyright, with all rights reserved, unless otherwise indicated.

\title{
Fatigue and fracture assessment of toxic metal replacement coatings for aerospace applications
}

PLEASE CITE THE PUBLISHED VERSION

http://dx.doi.org/10.1179/002029610X12734927543067

PUBLISHER

Maney Publishing ( Institute of Metal Finishing

VERSION

AM (Accepted Manuscript)

LICENCE

CC BY-NC-ND 4.0

REPOSITORY RECORD

Cree, A.M., M. Devlin, Gary W. Critchlow, and T. Hirst. 2012. "Fatigue and Fracture Assessment of Toxic Metal Replacement Coatings for Aerospace Applications". figshare. https://hdl.handle.net/2134/9636. 
This item was submitted to Loughborough's Institutional Repository (https://dspace.lboro.ac.uk/) by the author and is made available under the following Creative Commons Licence conditions.

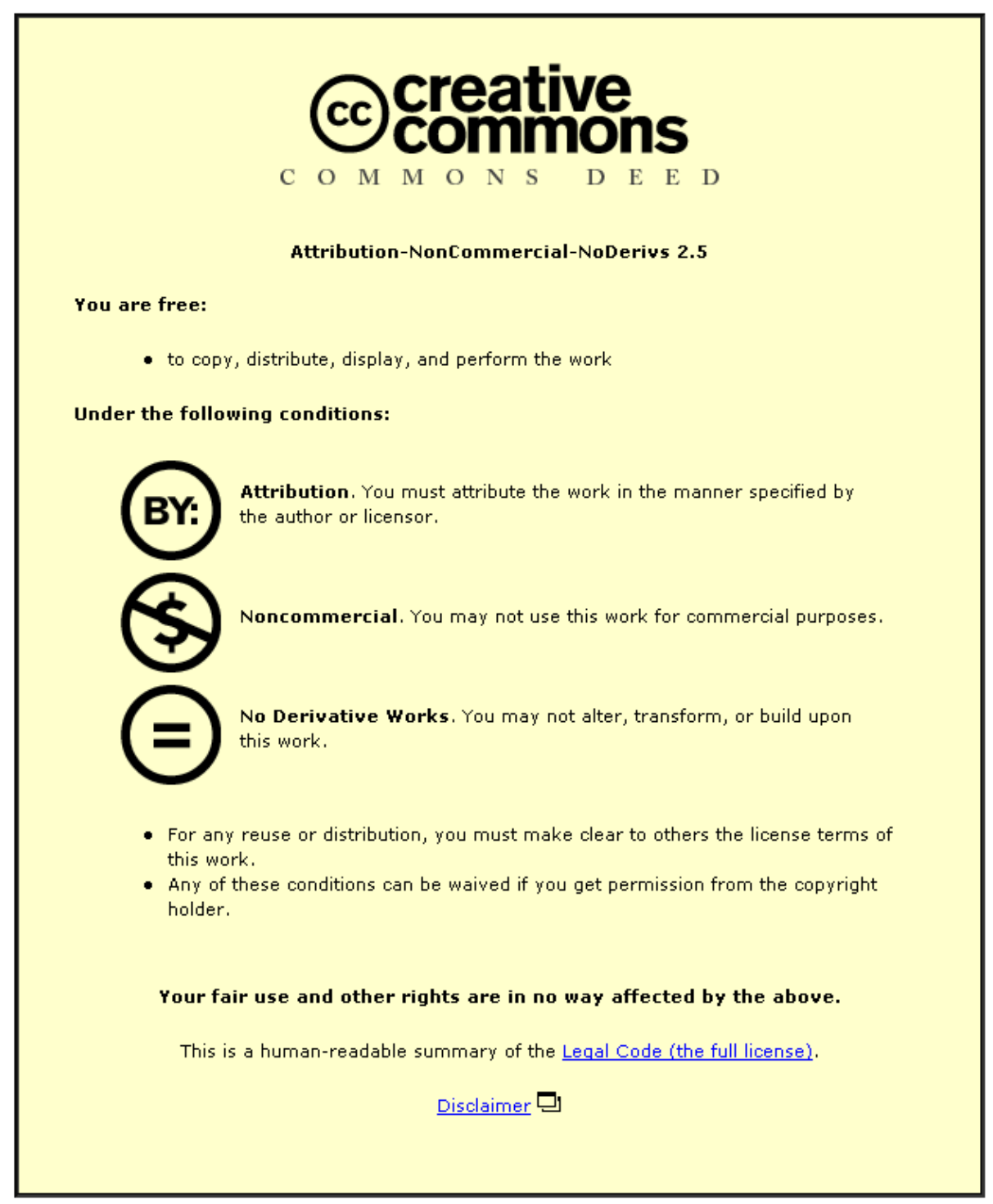

For the full text of this licence, please go to: http://creativecommons.org/licenses/by-nc-nd/2.5/ 


\title{
Fatigue and fracture assessment of toxic metal replacement coatings for aerospace applications.
}

\author{
A. M. Cree ${ }^{*} 1$, M. Devlin ${ }^{2}$, G. Critchlow ${ }^{2}$ And T. Hirst $^{3}$ \\ ${ }^{1}$ University of Plymouth at Britannia Royal Naval College, Dartmouth. \\ Devon TQ6 OHJ, United Kingdom. \\ ${ }^{2}$ Materials Department, Loughborough University, Loughborough. \\ Leicestershire LE11 3TU, United Kingdom. \\ ${ }^{3}$ Aero Engine Controls, Birmingham. \\ West Midlands B28 8SW, United Kingdom. \\ * Corresponding author, email: brnc-engsci2@nrta.mod.uk.
}

\begin{abstract}
The use of corrosion resistant, and adhesion promoting films and coatings is established industrial practice for many fatigue sensitive components and structures. However, recent environmental legislation restricting the use of a range of toxic heavy metals and their derivative processes, such as chromic acid anodising (CAA), has meant that a number of new coatings systems and pretreatments are currently being developed to replace the traditional processes still in use. Typical of these new systems are the boric acid-sulphuric acid anodising (BSAA) process which can be modified to provide excellent adhesive bonding properties; the sulphuric acid anodising process, which includes an additional electrolytic phosphoric acid deoxidizing stage (EPAD) to produce a duplex oxide layer, and the recently patented ACDC sulphuric acid anodising process which produces a two layered oxide film which can be tailored to produce different porosity volume fractions within each layer. This communication reports the preliminary findings of a study carried out to assess the fatigue response of Al2618:T6 aluminium alloys to these new processes. In contrast to CAA anodising, the initial results indicate that the EPAD and ACDC processes do not appear to have a significant affect on fatigue.
\end{abstract}

KEYWORDS: Anodising, fatigue, adhesion, replacement coating systems..

\section{INTRODUCTION}

Any engineering component can fail when its surface degrades in response to the imposed forces or environmental conditions it encounters in service. To minimise the impact of these problems a variety of coating systems have been developed which improves both the chemical and mechanical integrity of the underlying material, particularly in relation to corrosion resistance, wear and also when adhesive bonding is likely to be carried out. For most aerospace applications of high strength aluminium alloys, the required improved properties are usually achieved by anodising the component prior to service. This electrolytic process produces a much thicker oxide film, typically $2-10 \mu \mathrm{m}$, than would form naturally. For the adhesion of structurally significant items, chromic acid anodising (CAA) [1] and, to a lesser extent, phosphoric acid anodising (PAA) [2] are usually preferred options. However, the results of numerous studies $[3,4,5,6]$ have shown that any form of anodising is potentially harmful to the fatigue and fracture properties of the underlying substrate material. Consequently, the benefits gained in terms of corrosion protection, or improved adhesive bonding properties, must always be weighed against the incurred penalty of a reduction to the fatigue strength of the component.

The main contribution of anodising to fatigue is that of encouraging crack initiation so leading to premature failure [7]. In this respect all anodising processes are detrimental although CAA, which produces a slightly more flexible film, has only a small effect provided the film is kept thin (typically $2-3 \mu \mathrm{m}$ ) and established industrial practice strictly adhered to. However, the use of CAA is currently being phased out for reasons of its inherent toxicity. Of particular concern is the emission of hexavalent chromium vapour during the anodising process. Existing, and planned legislation has stimulated the development of several less toxic alternatives. At the present time the most 
useful replacement candidate for CAA appears to be the boric-sulphuric acid anodising (BSAA) process. This modified sulphuric acid process allows thin (typically 1-3 $\mu \mathrm{m}$ ) and compact oxide films to be formed consistently and has the added advantage of being cheaper to make up and operate. It is claimed [8] that BSAA is equivalent to CAA in all respects including corrosion resistance, paint adhesion and fatigue performance. In recent years the BSAA process has become fully accepted as an appropriate replacement for CAA and is currently in use on many US military aircraft. It should be noted that significant modifications are required to the standard BSAA process to facilitate acceptable structural adhesion.

This communication reports the preliminary findings of a study initiated to assess the fatigue and fracture response of A12618:T6 aluminium alloy which had been anodised using a variety of new, modified and established electrolytic processes. In particular, the following were investigated during the present study:

- chromic acid anodising, in both the unsealed and hot water sealed conditions, presented mainly for comparison purposes as the accepted European standard pre-treatment prior to adhesive bonding in both aerospsace and defence sectors;

- the recently patented [9] AC-DC mixed sulphuric acid-phosphoric acid anodising process which produces a tailored two layer oxide film with improved adhesion characteristics, and ;

- sulphuric acid anodising modified to include an additional electrolytic phosphoric acid deoxidising stage (EPAD). This process also produces a duplex oxide film with improved adhesion qualities.

The processing parameters required to produce these anodised films are detailed in section 2.1.

\subsection{Anodising and fatigue}

Despite its many benefits, anodising has been shown to adversely affect fatigue performance [4]. Of the two stages of fatigue, namely crack initiation and crack growth, most attention has been concentrated on initiation [7]. Anodised films are hard and brittle and readily crack when deformed. Since the oxide film grows out from the substrate, and is very adherent to it, any cracks or processing flaws which develop in the film act as stress raisers and will contribute many potential initiation sites for fatigue failure. An example of severe surface cracking is shown below in Figure 1 for a CAA film, in the unsealed condition, as tested during the present study.

The contribution of surface cracking to fatigue has been shown to depend on the type of anodising process employed and the thickness of the oxide film produced [10], the base substrate material [5], and the presence of residual stresses after sealing [11]. A reduction to fatigue life of up to $30 \%$ is commonly observed during stress-life (S-N) testing of the most deleterious types of anodising. However, through the strict adherence to standard industrial practise this effect can be reduced to more acceptable levels, although it may not be eliminated entirely. S-N data from a previous study [12] for Al2024:T4 aluminium alloy anodised using the BSAA process is shown below in Figure 2. In this instance a $22 \%$ reduction to fatigue strength was observed.

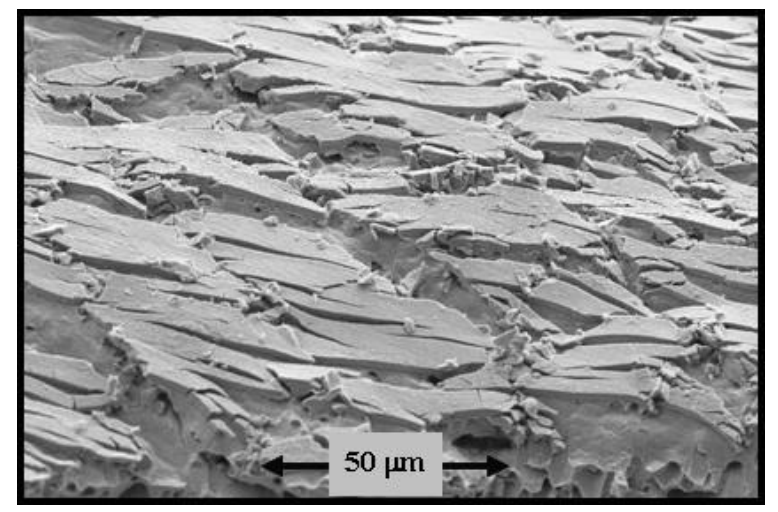

Figure 1: FEGSEM image of surface cracking on a CAA aluminium alloy. 
Although the influence of anodising on fatigue crack initiation is quite well understood, additional evidence presented in the literature $[13,14,15]$ suggests that fatigue crack growth rates can also be influenced by the presence of a thin surface film or coating. This aspect of the problem was not considered further in this study.

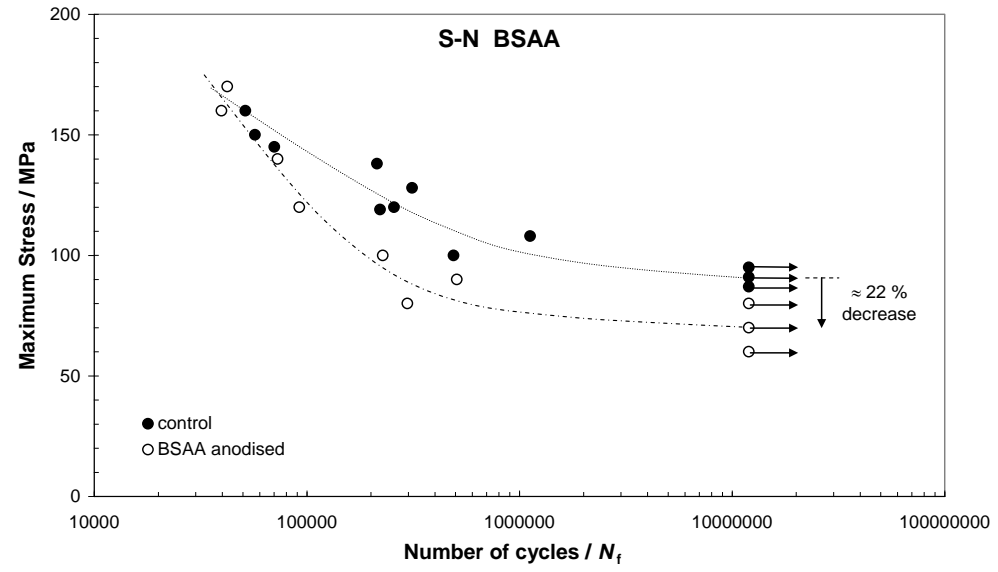

Figure 2: S-N data for BSAA Al2024:T4 aluminium alloy [11].

\subsection{Anodising and adhesion}

To promote good adhesion to a subsequently applied polymer such as an adhesive, primer or paint layer three commonly used anodising processes are sulphuric acid anodising (SAA), phosphoric acid anodising (PAA) and chromic acid anodising (CAA) [16]. For most aerospace and other important structural applications the process of choice is normally CAA although PAA is also extensively used, particularly in the US where it is the subject of the Boeing specification BAC 5555. Where CAA is the norm, it is essential that the original Bengough-Stuart process [1], viz. the 40-50 volt cycle process, is applied without any modification to the processing parameters since such modifications have been shown [17] to produce films which perform less well in adhesion tests. To facilitate adhesion, the surfaces to be bonded must be chemically and mechanically clean, i.e free from contamination and corrosion, and be highly wettable by the adhesive to be used. An appropriate level of cleanliness is achieved via a variety of pretreatment processes which normally include agitated cleaning in organic and inorganic solvents followed by surface etching, or pickling and rinsing in de-ionised water prior to anodising. The anodising process itself ensures that the adherends have sufficient macro, and micro, surface roughness to adequately "key" with the primer/adhesivea by producing a porous surface oxide film with a greatly increased specific surface area. This increased surface area is further enhanced by leaving the anodised film in the unsealed condition so that much of the natural film porosity is retained. To achieve this optimum condition it is important that the anodised surface is immediately dried at a moderate temperature (usually $\sim 50^{\circ} \mathrm{C}$ ) post anodising to prevent the onset of sealing.

\section{EXPERIMENTAL PROCEDURES}

\subsection{Material and specimen geometry}

The material chosen for fatigue testing was the high strength aluminium alloy A12618:T6, a traditional creep resistant alloy originally developed as "hiduminium" (RR58) - a structural material used on aircraft where moderately elevated operating temperatures are encountered. This alloy was widely used on Concorde where a supersonic cruise speed could raise the aircraft nose and fuselage to temperatures approaching $130^{\circ} \mathrm{C}$ for extended periods of time. As well as being used in sheet form for fuselage sections Al2618:T6 is also used for specific engine applications such as pump casings, bleed valves, guide vanes etc. again where a good level of elevated temperature strength is required. It is also used as a forging material for piston assemblies used in high performance motor vehicles. The chemical composition of the modern version of Al2618:T6, which can maintain a good level of strength up to about $150^{\circ} \mathrm{C}$, is given in Table 1 below.

\begin{tabular}{|c|c|c|c|c|c|c|}
\hline $\mathrm{Al}$ & $\mathrm{Cu}$ & $\mathrm{Mg}$ & $\mathrm{Fe}$ & $\mathrm{Ni}$ & $\mathrm{Si}$ & $\mathrm{Ti}+\mathrm{Zr}$ \\
\hline 93.45 & 2.3 & 1.5 & 1.2 & 1.1 & $0.25_{\max }$ & 0.2 \\
\hline
\end{tabular}

Table 1: Chemical composition of Al2618:T6 alloy. 
In the T6 condition, i.e. solution treated and artifically aged, A12618:T6 has a fully developed microstructure containing many second phase precipitates and intermetallics, as shown in Figure 3. For this alloy the copper and magnesium alloying elements contribute to strengthening through precipitation hardening by forming $\mathrm{Al}_{2} \mathrm{CuMg}$ (the lighter particles shown). In addition, the nickel and iron form a second intermetallic compound $\mathrm{Al}_{9} \mathrm{FeNi}$ (the darker particles) which assists hardening and helps to stabilize the microstructure via a dispersion mechanism. The inclusion of a small amount of silicon ( $0.25 \%$ max in this alloy) also promotes a more uniform dispersion of the $\mathrm{Al}_{2} \mathrm{CuMg}$ precipitates.

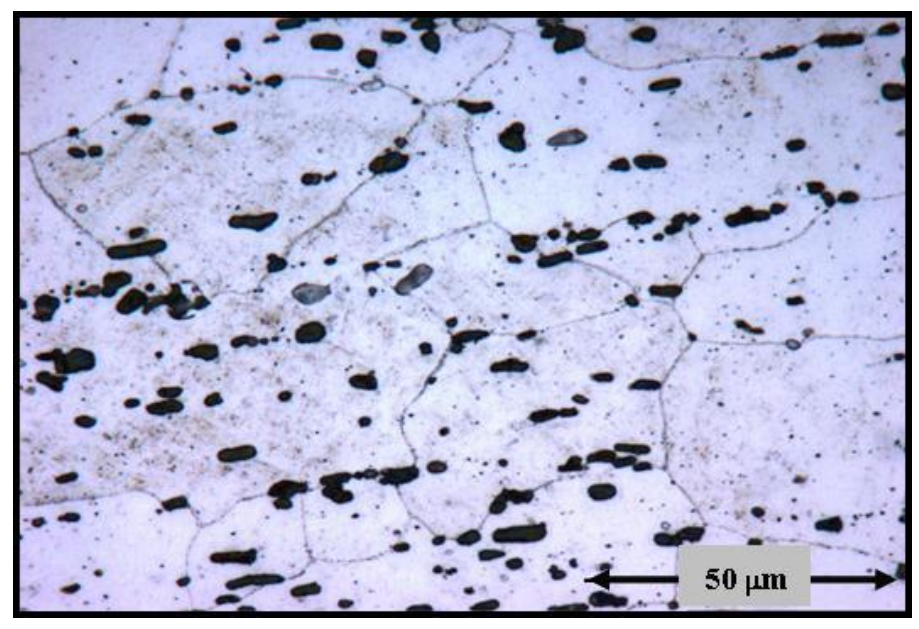

Figure 3: Typical microstructure for Al2618:T6 alloy.

During creep in this alloy, the primary deformation mechanism involved is one of combined dislocation glide and diffusion assisted climb. Consequently the creep rate is controlled by the ease with which the moving dislocations within the material can interact with, and ultimately overcome, the obstacles presented by the precipitates and intermetallics uniformly dispersed throughout the microstructure. The presence of such a considerable volume of stable particles gives A12618:T6 the excellent creep resistance it needs to operate at the slightly elevated temperatures encountered in service. However, the down side to the presence of these precipitates is the relatively low fracture toughness they also impart to the alloy, viz. $\mathrm{K}_{\mathrm{Ic}} \approx 20 \mathrm{MPa} \sqrt{\mathrm{m}}$ for Al2618:T6 compared to $\mathrm{K}_{\mathrm{Ic}} \approx 20-40$ $\mathrm{MPa} \sqrt{\mathrm{m}}$ for other high strength $2 \mathrm{xxx}$ series alloys. This relatively low fracture toughness leaves the alloy vulnerable to fatigue failure. In addition, in the T6 condition Al2618 is also known [18] to be susceptible to stress corrosion cracking (SCC) in the short-transverse direction, particularly if subjected to a sustained moderately high tensile load. This susceptibility to SCC is caused by the presence of the alloying elements copper, magnesium and silicon which often form, but not exclusively, at grain boundary precipitates.

The material to be anodised and fatigue tested was supplied as extruded bar in the T6 condition. From this material five batches of specimens ( $\approx 16$ in each batch), of the geometry shown in Figure 4, were machined and then crosshatch polished with 1200 grade emery paper.
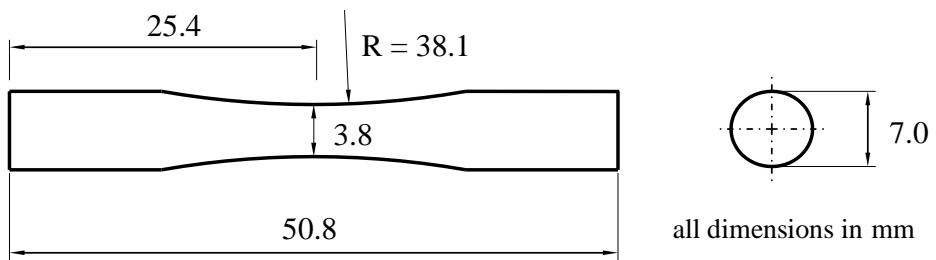

all dimensions in $\mathrm{mm}$

Figure 4: Fatigue specimen geometry. 
A toroidal specimen geometry was chosen to facilitate testing of the material using a simple rotating bend test [19] and to ensure that failure would occur at the narrowest section and not at the grips. All fatigue testing was conducted in accordance with B.S 3158 [20].

\begin{tabular}{|c|c|c|c|}
\hline $\begin{array}{c}\text { Process } \\
\text { Parameters }\end{array}$ & $\begin{array}{c}\text { Chromic Acid } \\
\text { Anodising }\end{array}$ & $\begin{array}{c}\text { AC - DC Process } \\
\text { (SAA - PAA) }\end{array}$ & EPAD + SAA \\
\hline Electrolyte Composition & $40 \mathrm{gl}^{-1} \mathrm{CrO}_{3}$ & $\begin{array}{c}2.5 \mathrm{gl}^{-1} \mathrm{H}_{2} \mathrm{SO}_{4} \\
2.5 \mathrm{gl}^{-1} \mathrm{H}_{3} \mathrm{PO}_{4} \\
\text { (mixed electrolyte) }\end{array}$ & $\begin{array}{c}\text { EPAD:200 gl }{ }^{-1} \mathrm{H}_{3} \mathrm{PO}_{4} \\
\text { SAA:40 } \mathrm{gl}^{-1} \mathrm{H}_{2} \mathrm{SO}_{4} \\
\text { (sequential not mixed) }\end{array}$ \\
\hline $\begin{array}{c}\text { Electrolyte Temperature } \\
\left({ }^{\circ} \mathrm{C}\right)\end{array}$ & $40 \pm 2^{\circ} \mathrm{C}$ & $35 \pm 2^{\circ} \mathrm{C}$ & $\begin{array}{l}\text { EPAD: } 30 \pm 3^{\circ} \mathrm{C} \\
\text { SAA: } 35 \pm 3^{\circ} \mathrm{C}\end{array}$ \\
\hline Anodising Time (min) & $40 \pm 1 \mathrm{~min}$ & $\begin{array}{c}2 \pm 1 \min \mathrm{AC} \\
10 \pm 1 \min \mathrm{DC}\end{array}$ & $\begin{array}{l}\text { EPAD: } 10 \pm 1 \mathrm{~min} \\
\text { SAA: } 20 \pm 1 \mathrm{~min}\end{array}$ \\
\hline Voltage (volts) & $40-50 \pm 1 \mathrm{~V}$ & $\begin{array}{l}\text { AC: } 15 \pm 1 \mathrm{~V} \\
\text { DC: } 20 \pm 1 \mathrm{~V}\end{array}$ & $\begin{array}{l}\text { EPAD: } 7 \pm 1 \mathrm{~V} \\
\text { SAA: } 15 \pm 1 \mathrm{~V}\end{array}$ \\
\hline $\begin{array}{l}\text { Anodising Voltage } \\
\text { Regimes }\end{array}$ & \multicolumn{3}{|l|}{$\begin{array}{r}70 \\
60 \\
\geq \quad 50\end{array}$} \\
\hline Additional Details & $\begin{array}{l}\text { CAA and EPAD+S } \\
\text { followed by a final } \\
\text { filtered and modera } \\
\text { anodising. One batc } \\
\text { water seal at } 96^{\circ} \mathrm{C} \mathrm{p} \\
\text { (ramped) slowly unt } \\
\text { done to prevent "bur }\end{array}$ & $\begin{array}{l}\text { cimens both receivec } \\
\text { ed water rinse. All e } \\
\text { itated using an auto } \\
\text { AA specimens also } 1 \\
\text { dising. In all cases t } \\
\text { equired processing v } \\
\text { f the oxide films. }\end{array}$ & $\begin{array}{l}\text { Initial vapour degreasing } \\
\text { plytes were continuously } \\
\text { d stirring system during } \\
\text { ed a } 12 \pm 2 \text { minute hot } \\
\text { plied voltage was raised } \\
\text { e was reached. This was }\end{array}$ \\
\hline
\end{tabular}

Figure 5: Anodising processing parameters for Al2618:T6 alloy.

\subsection{Anodising procedures}

Prior to fatigue testing four batches of specimens were anodised in accordance with the processing schedules detailed in Figure 5. Two of batches were chromic acid anodised, with one of these receiving a boiling water seal directly after anodising. The other two batches received the alternative anodising treatments (EPAD+SAA and ACDC) as described. A fifth batch of specimens was left to be tested in the as-received (control) condition in order to provide a comparison to the fatigue response of the anodised material. In keeping with other wrought $2 x x x$ series aluminium alloys, chromic acid anodising of Al2618:T6 results in an anodic oxide film which can only be described as moderate, in terms of quality, particularly corrosion resistance. These film quality issues arise due to the presence of the alloying elements copper and magnesium which can cause voids or holes to form in the film. Examination of the anodic oxide films produced by these procedures, as detailed later, should give an indication of likely film quality in this respect. 


\subsection{Fatigue testing}

All fatigue tests were conducted in accordance with B.S 3158 [20] using fully reversed loading conditions on an Open University constructed rotating bend fatigue testing machine at room temperature and in laboratory air. The test frequency was $24 \mathrm{~Hz}$ (1440rpm). For fully reversed loading conditions the specimen is subjected to alternating tensile and compressive stress as it rotates, hence the applied mean stress is kept at zero, giving a stress ratio of $\mathrm{R}=$ $\sigma_{\min } / \sigma_{\max }=-1$. For convenience during fatigue testing the endurance limit $\left(\sigma_{\mathrm{e}}\right)$ for the material was set at $5 \times 10^{6}$ cycles. The S-N data obtained are presented in Figures 6(a), 6(b) and 6(c) respectively for each of the three anodising procedures considered. For comparison purposes the results obtained for the control material are also shown on each graph.

In the elastic range, i.e. $\sim 10^{3} \rightarrow 10^{6}$ cycles, the $\mathrm{S}-\mathrm{N}$ curve can be characterised, on a log-log scale, using the Basquin [21] relationship, viz. $\sigma_{\mathrm{a}}=\mathrm{C} \cdot 2 N_{\mathrm{f}}^{\mathrm{b}}$ where $\sigma_{\mathrm{a}}$ is the stress amplitude, $N_{\mathrm{f}}$ is the number of cycles to failure $\left(N_{\mathrm{f}}=2\right.$ load reversals per cycle), $\mathrm{C}$ is a material constant and $\mathrm{b}$ is the Basquin exponent. This relationship only applies when $R=$ -1 . The Basquin plots were obtained from the $\mathrm{S}-\mathrm{N}$ data ignoring the run-outs. The endurance limit, at the specified number of cycles, will equal the stress amplitude, i.e $\sigma_{\mathrm{e}}=\sigma_{\mathrm{a}}$. The derived Basquin plots for the anodised specimens tested, are shown in Figures 7(a), 7(b) and 7(c) respectively.

\subsection{Examination of anodised film}

Following fatigue testing a number of the failed specimens were examined using a LEO $1530 \mathrm{VP}$ scanning electron microscope (SEM). Where greater resolution was required, this instrument was also used in the field emission gun scanning mode (FEGSEM). The intention was not to rigorously quantify the film quality in terms of porosity, thickness, coverage etc. but rather just to observe the morphology of the anodic oxide films that were formed in order to assess any possible contribution this might make to fatigue failure. A number of SEM and FEGSEM images are presented and discussed later.

\section{$\underline{\text { S-N curves }}$}

(a) CAA

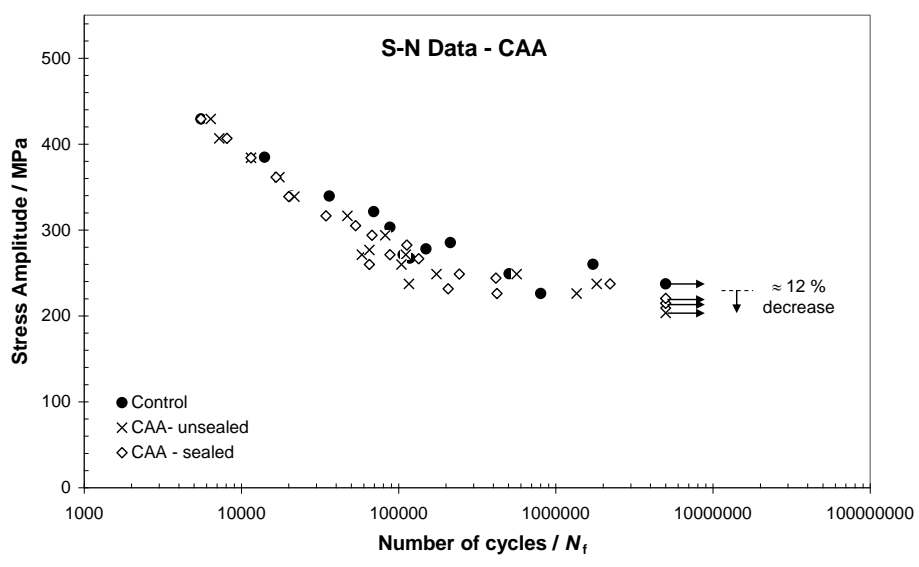

(b) ACDC

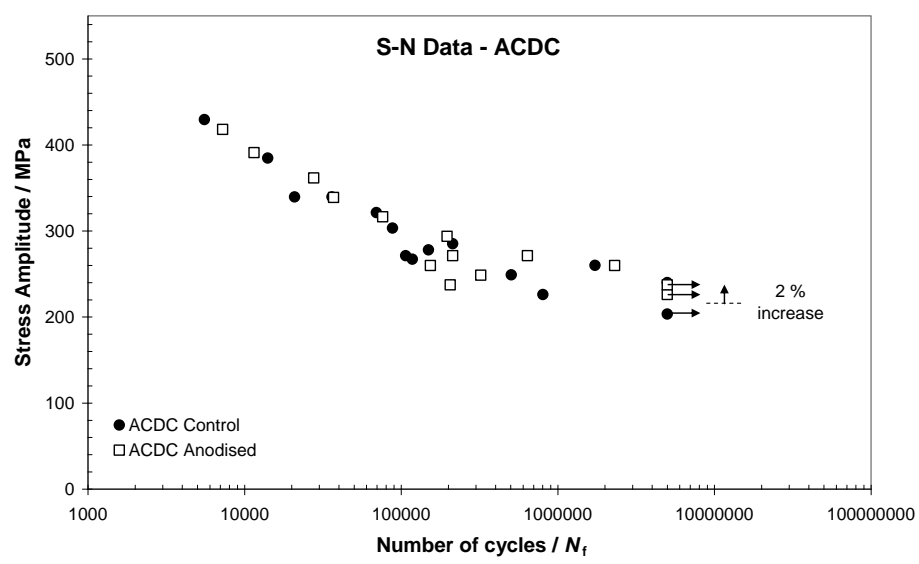


(c) EPAD

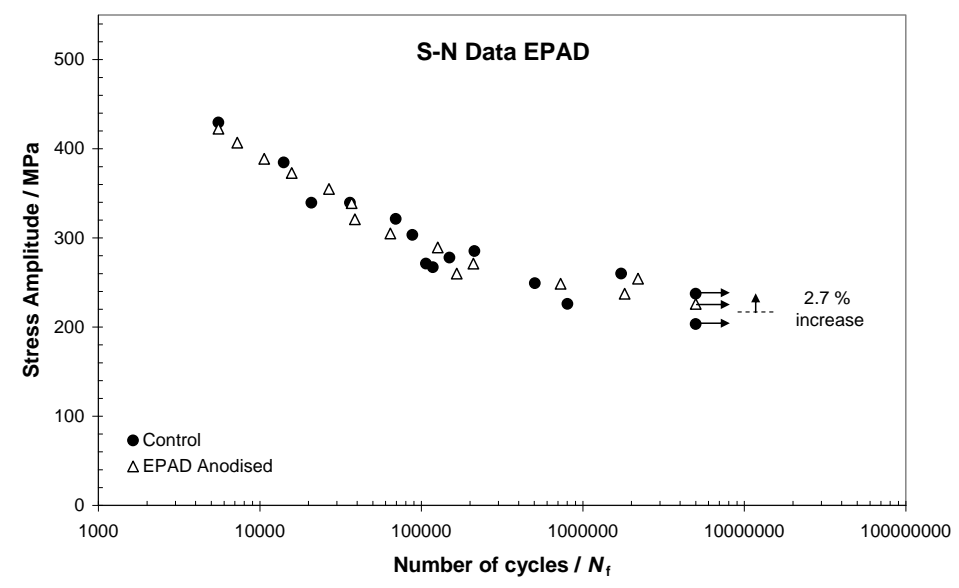

Figure 6: S-N data for anodised A12618:T6 aluminium alloy.

\section{Basquin analyses}

(a) CAA

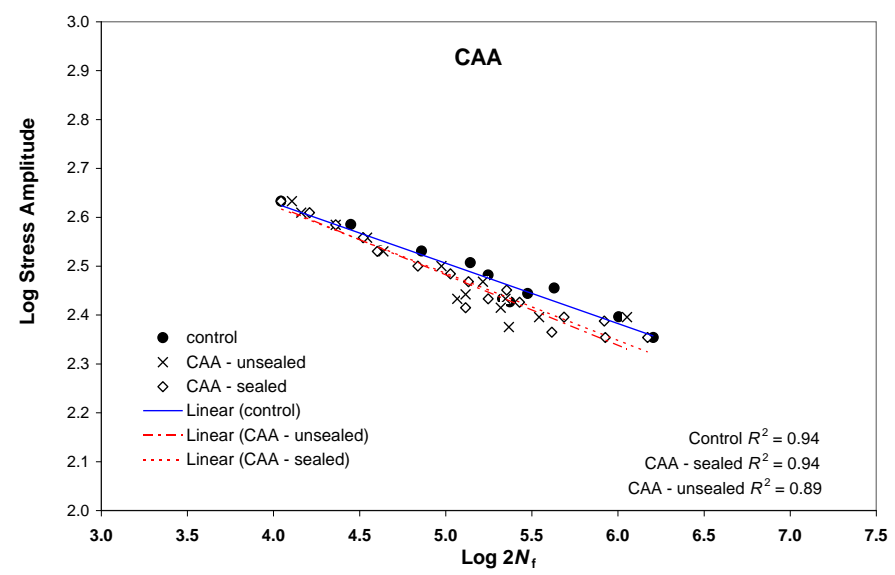

(b) $\mathrm{ACDC}$

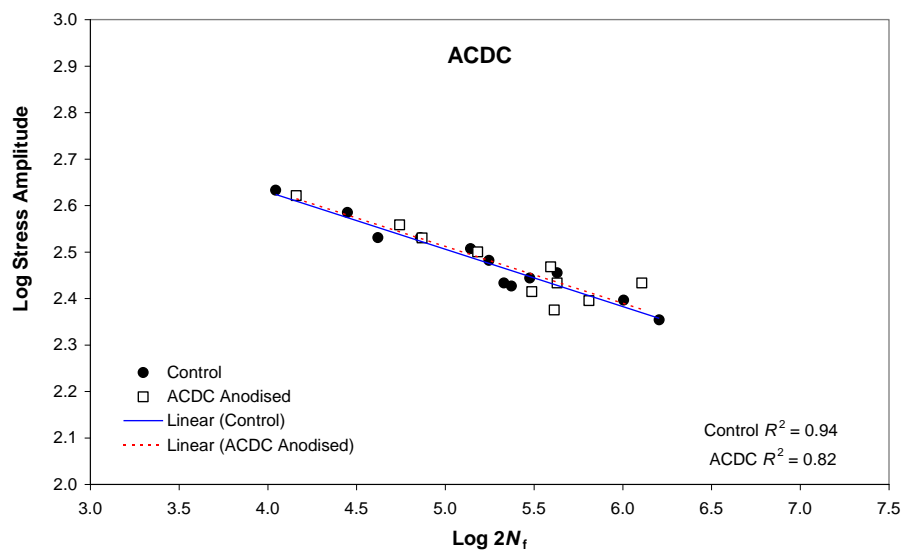


(c) EPAD

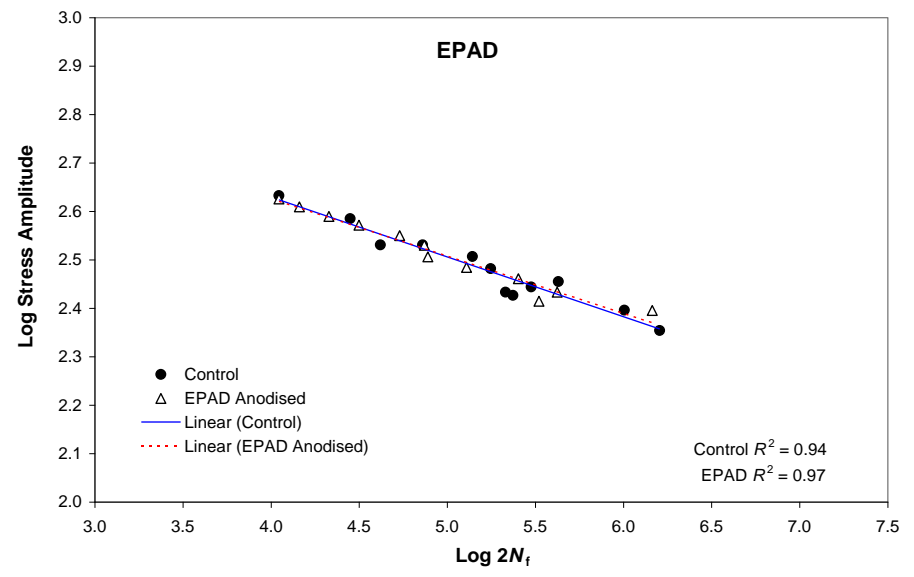

Figure 7: Basquin plots derived from S-N data for anodised Al2618:T6 aluminium alloy.

\section{DISCUSSION}

\subsection{Constant amplitude fatigue tests.}

From the S-N data shown in Figure 6, and the results obtained from the Basquin plots in Figure 7, it can be seen that CAA reduced the endurance limit of the alloy by approximately $12 \%$ in both the sealed and unsealed conditions. The extent of this reduction is very similar to other values quoted in the literature [4] and was as expected. The fatigue problems associated with anodising mainly arise because the films produced (which are essentially hydrated alumina, viz. böhemite) are hard and brittle and will readily crack when stressed. Consequently any film cracks which develop provide excellent conditions for the continued growth of the fatigue crack into the substrate material. This cracking process is also assisted by the presence of residual stress in the film [22]. The results obtained for the other processes, viz. EPAD and ACDC anodising, were encouraging and indicated that these processes had a less detrimental effect on fatigue performance. Surprisingly in both cases the presence of the anodic films appeared to actually increase the endurance limit of the underlying alloy, albeit by only a small amount $(\sim 2 \%)$. At this stage these anodic oxide films are not considered to be positively beneficial to the fatigue strength since the slight increases observed lie well within the bounds of normal scatter expected from fatigue tests of this type. Rather, they seem to possibly offer a less detrimental anodising effect to fatigue compared to the standard CAA process. In order to understand why these processes are less detrimental, one most first understand the role played by the initial oxide film fracture to the complete fatigue failure of the substrate material.

\subsubsection{The role of initial oxide fracture}

Fracture in an anodic oxide film is governed by the maximum tensile stress in the plane of the film with the magnitude of this stress depending upon the contributions made by both film and substrate. For a condition of reverse bending the total stress in the film will comprise the following components:

i. an extrinsic tensile stress due to the shear strain transmitted directly from substrate to film, via the interface region, due to the external loading, $\sigma_{\text {app }}$

ii. an intrinsic residual stress (usually tensile) in the film caused by growth processes as the oxide forms, $\sigma_{\text {res }}$

iii. an alternating tensile-compressive stress caused by the external bending of the substrate material, $\sigma_{\mathrm{b}}$.

For an anodised aluminium alloy undergoing reversed cyclic bending it is unlikely that component (i) will be significant since the anodised film is almost fully coherent with the substrate material beneath. Consequently the total applied tensile stress, $\sigma_{\mathrm{T}}$, will really only be due to the two remaining components, viz. $\sigma_{\mathrm{T}}=\sigma_{\mathrm{b}} \pm \sigma_{\text {res }}$. Under these condition $\sigma_{\text {Tmax }}$ will subject any defect present in the surface film to a significant mode I (opening mode) loading condition during the tensile part of the loading cycle. Hence $\sigma_{\mathrm{T} \max }=\sigma_{\mathrm{b}}+\sigma_{\text {res }}$. With this being so then a simple linear elastic fracture mechanics (LEFM) approach can be used to define the critical stress condition necessary for the onset of fracture. 
If we assume that the dominant crack is likely to develop by the growth of a pre-existing defect or flaw either within, or at the surface, of the oxide film then the condition for growth is simply;

$$
K_{\mathrm{Ic}} \leq \sigma_{\mathrm{Tmax}} \cdot \sqrt{\pi a_{\mathrm{i}}} \cdot \mathrm{Y}
$$

where $K_{\mathrm{Ic}}$ is the critical stress intensity factor for mode I static fracture, $a_{\mathrm{i}}$ is the initial defect size $(\approx$ film defect depth) and $\mathrm{Y}$ is a correction (compliance) factor for the defect geometry involved. Within the oxide film unstable static crack growth towards the film-substrate interface will occur when this condition is met. For the anodic oxide films considered in this study many film defects are readily available.

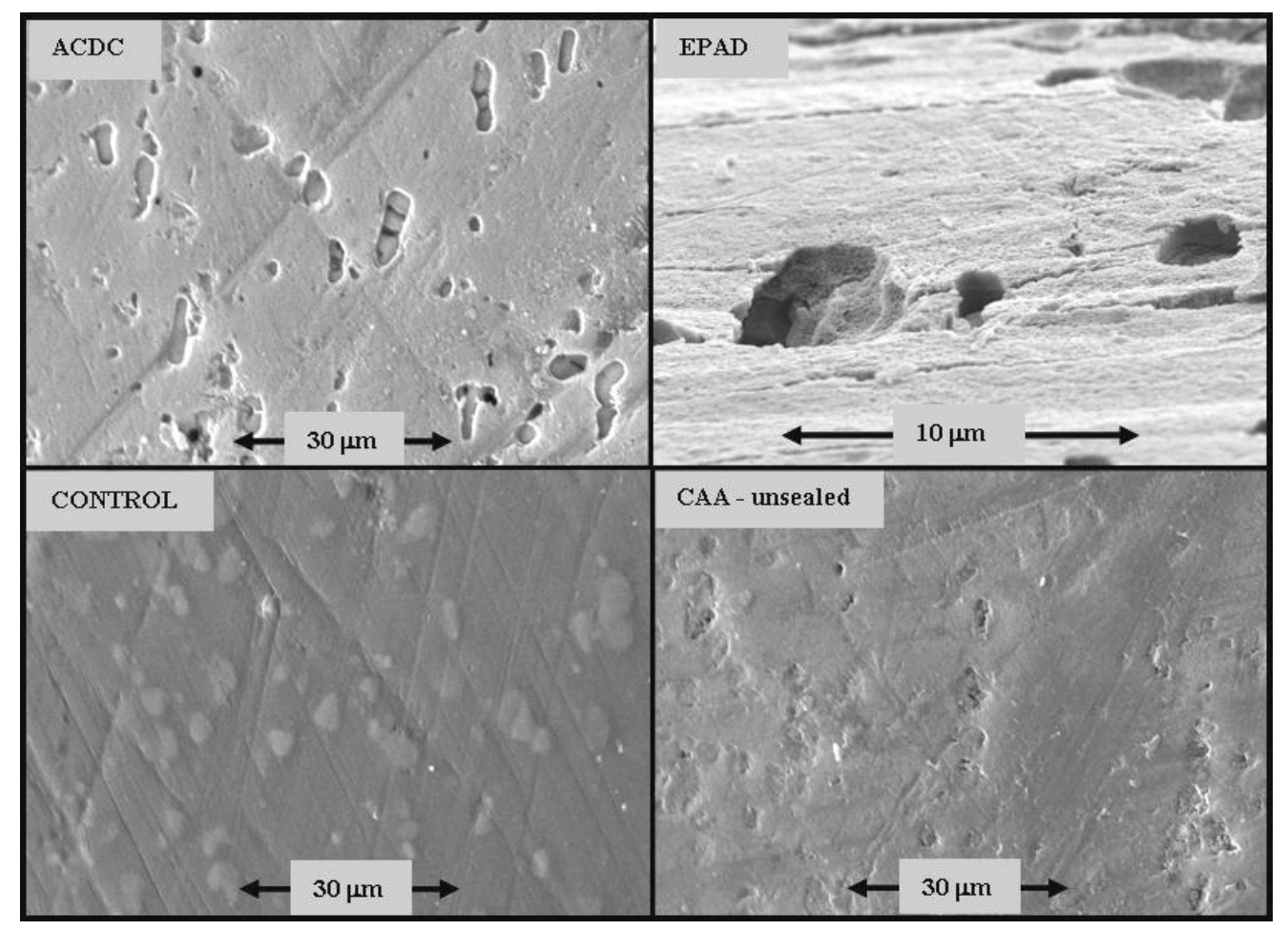

Figure 8: SEM and FEGSEM images showing films voids and the presence of surface layer second phase particles.

Figure 8 clearly shows the presence of numerous holes/voids in all of the anodic oxide films tested. Voids and holes of this type usually form in the film directly above second phase particles present in the surface layer of the substrate material. These surface piercing particles are clearly seen in the SEM image for the control material.

For a very adherent oxide film, with good strain compatibility across the interface, it is possible that the film will fracture (by virtue of the film's likely higher modulus) at strains where the deformation taking place in the substrate remains elastic. However, it is unlikely that fracture will occur in this way until a reasonably high level of static stress is reached in the film. It can be concluded therefore, that cyclic loading is also necessary to grow the initial defect in the oxide film to a substantive size where it can initiate a macro fatigue crack in the substrate material.

When the film crack, under continuing cyclic action, finally reaches the interface region between film and substrate then a number of different fracture events are possible. These are:

i. the film crack will immediately arrest at the interface and progress no further,

ii. the film crack will continue unimpeded into the substrate material for a distance and then arrest,

iii. the crack will deviate and grow along the interface region causing the film to spall or debond,

iv. the crack will penetrate through the interface and will continue to grow ultimately causing the full failure of the substrate material. 
Which of these events occurs is determined by the nature of the film-substrate interface. In this context an interface can be described as being either strong or weak [23]. If an interface is strong then slip can occur in the boundary layers of the substrate material adjacent to the interface. If this occurs then it is an important source of stress redistribution and relief (plastic dissipation). When sufficient plasticity is available then the interaction of the crack tip plastic zone with the interface may cause the crack to arrest by a simple blunting mechanism in the substrate material. It has been shown experimentally [24] that a crack advancing towards an interface between a tough (lower modulus) and a less tough (higher modulus) material, from the tough direction, would arrest at the interface. Crack growth in the reverse direction results in unimpeded growth through the interface, and possibly at an enhanced growth rate.

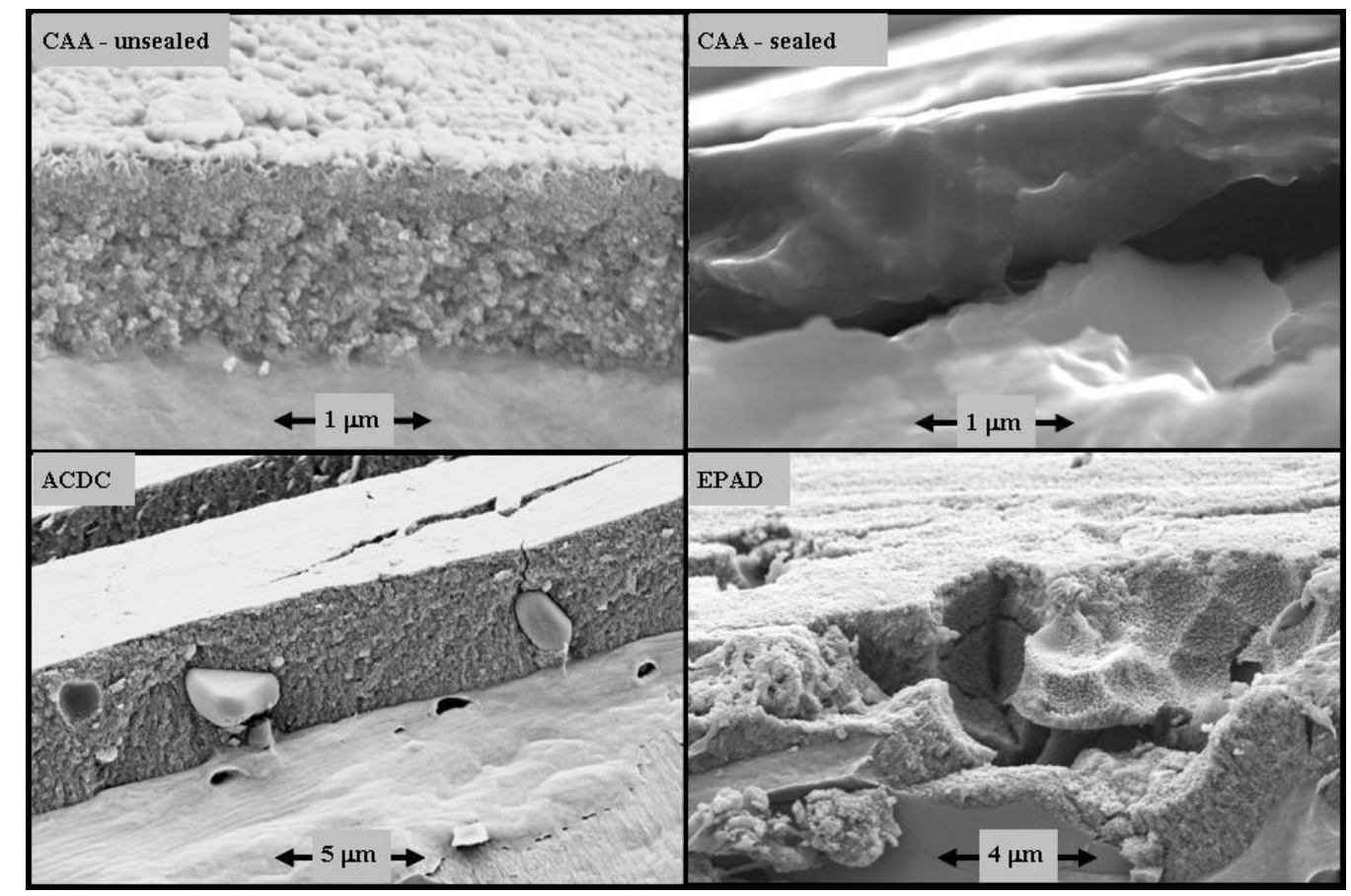

Figure 9: Anodised film morphologies.

When the region of plasticity adjacent to the interface is small, then simultaneous fracture and deformation events are possible. These so called weak interfaces allow for continued crack growth since the stress redistribution which occurs, through the interaction of the plastic zone with the interface, is limited. Consequently much larger interfacial shear stresses can develop at the crack tip. If the strength of adhesion between the film and substrate is poor, then the shear stress which develops allows the crack trajectory to follow the interface direction, and the film will delaminate. Where good interfacial adhesion exists, as is the cases with all anodic oxide films, then the crack can maintain its original trajectory perpendicular to the direction of the maximum tensile stress and will penetrate the interface region, enabling full fatigue failure of the substrate material.

The propensity of a film crack to fully penetrate the film-substrate interface can also be affected by the morphology of the anodic oxide film through which it has initially been growing. An indication of the nature of the film morphologies obtained are shown in Figure 9. If the oxide film produced is highly porous, as was the case for all of the films tested (except CAA in the sealed condition), then a percentage of the strain energy driving the crack forward will be dissipated by the numerous micro-fracture events occurring around the crack tip in the porous film before it reaches the interface region. This form of extrinsic toughening, which has been termed zone shielding [25], occurs when the advancing crack tip stress field encounters voids, holes or dilated regions in a material. This toughening mechanism is restricted to non ductile materials with a low fracture toughness, $\mathrm{K}_{\mathrm{Ic}}$. Therefore, it is postulated that the slightly more porous EPAD and ACDC anodic oxide films exhibit a higher level of zone 
shielding within the oxide film when compared to CAA. Although this greater porosity is not entirely evident in the images shown in Figure 10, there is some nanoindentation evidence [15] to confirm that CAA produces an oxide film which is slightly harder and more dense and compact, i.e. less porous, than the other processes tested. Hence EPAD and ACDC anodic oxide films are able to delay, but not eliminate, the onset of crack initiation in the subtrate material.

Finally, an interesting feature of the anodised film produced by the ACDC process, and one never previously observed, was the incorporation of a small number of second phase precipitates into the oxide film itself. An example of this unusual event is shown in Figure 10. These particles were confirmed, by point analysis, as containing copper and are therefore most likely to be $\mathrm{Al}_{2} \mathrm{CuMg}$ precipitates, as seen in the alloy microstructure in Figure 3. Some evidence also exists, in the form of surface holes and voids - see Figure 8, which indicates that a similar thing may also have been happening in the EPAD oxide film. However, no particles were found fully embedded in the EPAD films to confirm this speculation. It is also possible that such damage could also occur as a consequence of poor anodising directly above second phase precipitates in the surface layer of the substrate material. The mechanism by which these particles become incorporated in the film is not clear. However, it is likely to be related to the initial dissolution of the substrate material around these precipiates as the applied voltage is slowly ramped up to the required processing voltage. During this period it is possible that any surface piercing precipitates will be loosened so allowing electrolyte penetration, and thus film formation around, and under them, thereby incorporating them into the film. Although some cracking of the oxide film around these particles can be seen, there presence does not seem to affect the fatigue performance, given the fatigue results obtained for these two processes.

\section{CONCLUSIONS}

The results of this preliminary study have confirmed that the fatigue and fracture behaviour of Al2618:T6 aluminium alloy can be markedly affected by the presence of an anodic oxide film. From the S-N data obtained the magnitude of the effect was seen to be highly dependent upon the type of anodising process employed. For the CAA process a reduction to the endurance limit of $\sim 12 \%$ was observed for the anodised alloy in both the sealed and unsealed condition. For this process the observed reduction in the fatigue strength of the alloy can be attributed to the brittle nature of the film produced, assisted by the presence of process defects and a degree of residual stress. In combination these film attributes serve to facilitate a more rapid initiation of fatigue cracks in the underlying substrate material. In contradiction to the findings for the CAA process, the EPAD and ACDC anodising processes appeared to have a negligible effect on the fatigue performance of the underlying substrate material. No resulting loss to the fatigue strength of the alloy, up to $5 \times 10^{6}$ cycles, was observed. It is suggested that the improvement seen occurs as a result of delayed crack initiation in the substrate material, brought about by a greater degree of zone shielding proffered by the lower modulus, and more porous, anodised films in place.

\section{ACKNOWLEDGEMENTS}

Gratefully acknowledged is the materials support of Aero Engine Controls, which is the trading name of RollsRoyce Goodrich Engine Control Systems Ltd. The company designs and produces engine control systems and products for a variety of commercial and military aircraft. Also acknowledged is the optical and SEM microscopy support freely given by Mr. Terry Richards (University of Plymouth) and Mr. Graham Clark (University of Leicester).

\section{REFERENCES}

1. Bengough G.D and Stuart J.M. (1923). The anodic oxidation of aluminium and its alloys as a protection against corrosion. British Patent 223994. H.M Stationery Office, London, U.K.

2. Brockmann O.-D, Hennemann H, Kollek H and Matz C. (1986). Adhesion in bonded aluminium joints for aircraft construction. International Journal of Adhesion and Adhesives, 6, 3, pp. 115-143. 
3. Larssen S.E. (1975). The influence of anodising processes on the fatigue strength of aluminium alloys in a non-corrosive atmosphere. Proceedings of the 8th International Committee on Aeronautical Fatigue Symposium, Lausanne, France, section 2.6, pp. 1-47.

4. $\quad$ t'Hart W.D.J. and Nederveen A. (1980). The influence of different types of anodic layers on the fatigue properties of 2024-T4 and 7075-T6 sheet material. NLR Report No. TR80077U, National Aerospace Laboratory, Netherlands.

5. Wanhill R.L.H. (1985). The effects of cladding and anodising on flight simulation fatigue. NLR Report No. TR85006U, National Aerospace Laboratory, Netherlands.

6. Rateick R.G., Binkowski T.C. and Boray B.C. (1996). Effect of hard anodize thickness on the fatigue of AA6061 and C355 aluminium. Journal of Materials Science Letters, 15, pp. 1321-1323.

7. Abramovici E, Leblanc P. and Weaver B. (1991). The influence of etch pits on the fatigue life of anodized aluminum alloys: fractographic examaination. In Proceedings of the International Conference and Exhibits on Failure Analysis, 8-11 July, Montreal, Quebec, Canada.

8. Koop R and Moji Y (1992). Boric/sulphuric acid anodise - an alternative to chromic acid anodising. SAE Technical Report No. 920944. Society of Automotive Engineers, Warrendale, U.S.A, pp. 1-8.

9. Critchlow G.W, Ashcroft I, Cartwright T, and Bahrani, D. Anodising aluminium alloy. U.K. patent no. GB 3421959A.

10. Alvey C.E, Wood G.C and Thompson G.E (1974). The mechanical properties of porous anodic films formed on aluminium. Proceedings of the 10th World Congress on Metal Finishing, Kioto, Japan, pp. 275280 .

11. Karlashov A.V, Gainutdinov R.G. and A.T. Pankov (1976). Comparative study of the effect of anodizing and of cladding followed by anodizing on the cyclic strength of D16T sheet material, Soviet Materials Science, 12, 1, pp. 76-79.

12. Cree A.M. and Weidmann G.W (1997). The fracture and fatigue properties of anodised aluminium alloy. Transactions of the Institute of Metal Finishers, 74, 5, pp. 199-202.

13. TORII T. and HONDA K. (1992). Fatigue crack growth testing of films using pre-cracked base plates. Advances in Electronic Packaging, American Society of Mechanical Engineers, U.S.A: pp. 707-712.

14. LI Y.G.and QIAO J.S. (1992). Effects of brush electroplating and shot peening on the fatigue strength of a medium strength steel, Fatigue and Fracure of. Engineering Materials and Structures, 15, pp. 431-436.

15. Cree A. M., Weidmann G.W. and Hermann, R. (1995). Film-assisted fatigue crack propagation in anodised aluminium alloys. Journal of Materials Science Letters , 14, pp. 1505 - 1507.

16. Critchlow G.W. and Brewis, D.M. (1996). Review of surface pretreatments for aluminium alloys. International Journal of Adhesion and Adhesives, 16, pp. 255-275.

17. Critchlow G.W, Yendall K.A, Bahran D., Quinn A. and Andrews, F. (2006). Strategies for the replacement of chromic acid anodising for the structural bonding of aluminium alloys. International Journal of Adhesion and Adhesives, 25, pp. 419-453.

18. Rhodes D and Radon J.C. (1979). Environmental effects on crack propagation in aluminium alloys. Fatigue and Fracure of. Engineering Materials and Structures, 1, pp. 383-393.

19. Wöhler A. (1860). Versuche über die Festigkeit der Eisenbahnwagenachsen. Zeitschrift für Bauwesen 10. English summary in Engineering 4, pp. 160-161, (1867). 
20. British Standard 3518 (1987). Methods of fatigue testing. British Standards Institution, Linford Wood, Milton Keynes, U.K.

21. Basquin O.H. (1910). The exponential law of endurance tests. Proceedings of the American Society for Testing and Materials, 10, pp. 625-630.

22. Cree A.M. (2004). Accelerated Fatigue Crack Growth in High Strength Aluminium Alloys. Proceedings of the 4th International Conference on Thin-Walled Structures (ICTWS 4). Loughborough University, U.K, pp. 459-466.

23. Evans A.G. and Hutchinson J.W. (1995). The thermomechanical integrity of thin films and multilayers. Acta Metallurgica et Materialia, 43, 7, pp. 2507-2530.

24. Suresh S, Sugimura Y. and Ogawa T. (1993). Fatigue cracking in materials with brittle surface coatings. Scripta Metallurgica et Materialia, 29, pp. 237-242.

25. Ritchie R.O. (1988). Mechanisms of fatigue crack propagation in metals, ceramics and composites: role of crack tip shielding. Materials Science and Engineering, A103, pp. 15-28. 